\title{
ENCUADRE DE VEROSIMILITUD DE UN PERIÓDICO DE CIRCULACIÓN NACIONAL
}

\author{
En un periodo anterior y posterior a los comicios presidenciales de \\ 2012 en México
}

Lirios Cruz Garcial', Javier Carreón Guillén ${ }^{2}$,Jorge Hernández Valdés ${ }^{3}$

RESUMEN

Grosso modo, el establecimiento de una agenda pública supone la difusión sistemática de temas en los medios de comunicación con la finalidad de formar una opinión pública respecto a sus gobernantes. En materia de seguridad, los medios impresos desarrollan un encuadre o sesgo de difusión en contra o a favor de un sistema de administración pública, siguiendo dos lógicas:

1 Doctor en Gobernanza de la Complejidad. Centro de Estudios Politicos y Sociales. Universidad Autónoma del Estado de México. E-mail:Cgarcial213@profesor.uaemex.mx

2 Doctor en Administración. Profesor de la Universidad Nacional Autónoma de México.E-mail: javierg@unam.mx

3 Doctor en Trabajo Social, Universidad de la Plata.Profesor de la Universidad Nacional Autónoma de México. E-mail: joheval@unam.mx 
verosimilitud y verificabilidad, siendo determinantes de representaciones, opiniones, disposiciones, intenciones y acciones que se pueden observar en una contienda electoral y los comicios subsecuentes. En ese sentido es que el objetivo del presente trabajo consiste en el diagnóstico del encuadre de un periódico de circulación nacional en relación con el periodo que va de julio de 2011 a julio de 2012. Se realizó una investigación no experimental, documental, exploratoria y retrospectiva con una selección muestral no probabilística de 100 notas informativas. Los resultados muestran un encuadre o sesgo moderado con una lógica de verosimilitud antes de las elecciones y con una lógica de verificabilidad posterior a los comicios que no parecen haber influido en las preferencias, intenciones y sufragios de la elección presidencial de 2012. Se advierten líneas de investigación comparativas a sistemas, periodos y diarios.

Palabras clave: Seguridad, agenda, encuadre, verosimilitud, verificabilidad

\section{ABSTRACT}

Roughly speaking, the establishment of a public agenda presupposes the systematic dissemination of topics in the media in order to form a public opinion regarding its rulers. In terms of security, the print media develop a bias or diffusion bias against or in favor of a system of public administration, following two logics: verisimilitude and verifiability, being determinants of representations, opinions, dispositions, intentions and actions that can be observed in an electoral contest and the subsequent elections. In this sense, the objective of the present work is the diagnosis of the framing of a newspaper of national circulation in relation to the period from July 2011 to July 2012. Non-experimental, documentary, exploratory and retrospective research with a non-probabilistic sample selection of 100 informative notes. The results show a moderate frame or bias with a verisimilitude logic before the elections and with a logic of verifiability after the elections that do not seem to have influenced the preferences, intentions and votes of the presidential election of 2012. Lines of Comparative research to systems, periods and journals.

Keywords: Security, agenda, framing, verisimilitude, verifiability

$\mathrm{E}$ presente artículo se inscribe en la disciplina de Trabajo Social, área de estudios mediáticos, pero incluye conceptos relativos a la psicología social como es el caso del procesamiento de información, de la sociología de la información como es el caso del encuadre de verificabilidad y verosimilitud, así como desde las ciencias de la comunicación como es el caso del establecimiento de la agenda.

De este modo, el encuadre de verosimilitud es entendido desde la psicología social como un instrumento de influencia de los medios de comunicación sobre las audiencias, pero ello supone desmarcarlos del tipo del encuadre de verificabilidad ya que, ambos encuadres, verosimilitud y verificabilidad son más que dos instrumentos de influencia mediática. Esto es así porque se trata de estilos de comunicación preponderantes en la relación entre televisión, radio o prensa sobre sus audiencias.

Empero, los encuadres de verosimilitud y verificabilidad son también indicativos de un fenómeno más global como es el caso del establecimiento de la agenda pública, la cual es definida como un escenario de ejes y temas de discusión debatibles y consensuados por actores políticos y sociales, públicos y privados.

De este modo, el encuadre de verosimilitud es más que un instrumento de influencia mediática y forma parte de un sistema de gestión y administración de información orientada a establecer una agenda pública en la que la sociedad civil estará inmersa en los temas que la televisión, la radio o la prensa han difundido a partir de sus intereses particulares sin considerar las necesidades y las expectativas de sus audiencias ni las capacidades de quienes las gobiernan.

Por consiguiente, el objetivo del presente trabajo es explorar el encuadre de verosimilitud que prevalece en las audiencias de los medios impresos respecto a los comicios presidenciales de 2012 en México, particularmente el análisis del periódico "El Universal", pero con énfasis en sus implicaciones cíclicas para las elecciones federales de 2018.

\section{Teoría del procesamiento de información de las audiencias}

El establecimiento de la agenda, para los fines del presente trabajo, refiere a la difusión intensiva de temas en la ciudadanía con la finalidad de incidir en las políticas. La clave de este fenómeno ha sido identificada como encuadre de la información (García, 2012). Es así como los medios impresos han sido estudiad os desde dos estrategias de influencia en los lectores: lógica de verosimilitud y lógica de verificabilidad (Acosta, 2010). 
Si los periódicos dedican sus primeras planas a la difusión de información concerniente a la seguridad pública y la encuadran desde conceptos negativos como "sicario", "lugarteniente" o "ajuste de cuentas", entonces prevalece una lógica de verosimilitud consistente en ajustar las notas de prensa o las columnas de opinión a un imaginario social o apología del delito (González et al., 2011). En esencia, esta lógica de verosimilitud incide en lectores que construyen un criterio de búsqueda, análisis y opinión de la seguridad de su país o localidad a partir de columnas periodísticas (Guardiola, Espinar y Hernández, 2010). Se trata de lectores que reaccionan a las notas con emociones de indignación, zozobra o enojo y son proclives a firmar desplegados o pliegos petitorios, realizar mítines o confrontarse con las autoridades (Añez, Rujano y Párraga, 2011).

En contraste, si los rotativos más bien diversifican la información de sus columnas principales y sus contenidos están centrados en información de organizaciones civiles o instituciones estatales, entonces contribuyen al desarrollo de una lógica de verificabilidad, la cual consiste en comparar la información de los medios impresos con los hechos, anticipando escenarios a partir de la tendencia estadística (García, 2013). Los lectores asiduos de esta lógica de verificabilidad tienen un perfil especializado, son profesionistas $\mathrm{y} / \mathrm{o}$ autodidactas ya que procesan la información a partir de las diferencias y las similitudes entre las notas de prensa con los hechos globales o locales. Además, estos lectores se distinguen por producir información que contribuya a una discusión y a un consenso público (Borghello y Temperi, 2012).

En ambos encuadres, lógica de verosimilitud y lógica de verificabilidad, cuando inciden sobre lectores que no responden con emociones o razonamientos y más bien se mantienen indiferentes, subyace un encuadre y lógica colateral, la cual explica un aumento sustancial de la verosimilitud y la verificabilidad ya que los periódicos intensifican aún más su difusión al observar que sus lectores se mantienen indiferentes a sus notas o columnas de opinión (Calderón, 2012).

Si los estudios del establecimiento de la agenda se dirigen a explicar las relaciones existentes entre los contenidos de los medios de comunicación, los temas de opinión pública y las estrategias de las políticas públicas, entonces los estudios del efecto encuadre advertirán que el estilo de encuadre y penetración mediática incide directamente en la socialización de la ciudadanía ( $\mathrm{Gu}$ y Goldfarb, 2010).

Se trata de un círculo vicioso o virtuoso en el que la difusión de los hechos es un indicador de ingobernabilidad o democracia que retroalimenta los temas de discusión de la agenda ciudadana (González, Hernández y Garza, 2010). En referencia a la amplitud de los medios de comunicación, los regímenes autoritarios parecen construir relaciones de desconfianza y las democracias parecen construir relaciones de confianza entre los ciudadanos, los medios y la clase política (Salas, 2011). Ello supone que los medios impresos intensifican una lógica de verosimilitud en los regímenes autoritarios y una lógica de verificabilidad en los gobiernos democráticos, pero si emerge un encuadre colateral, entonces ambos encuadres y lógicas se intensifican a la par en cualquier tipo de Estado (Carcelén, Esteba y Peyró, 2013).

\section{Estudios del procesamiento de información de las audiencias}

Groshek (2011) encontró relaciones positivas y significativas entre tres medios de comunicación (televisión, radio y prensa) con respecto a la situación sociopolítica de 122 países. A medida que el encuadre y penetración de los medios se intensificaba, contribuía con el aumento de prácticas democráticas. Las diferencias existentes entre la televisión, radio y prensa corroboraron el supuesto en torno al cual los medios de comunicación contribuyen en la construcción de una democracia participativa. La prensa y su reducido encuadre se diferenciaban 
respecto a los niveles de expectación correspondientes a los otros dos medios de comunicación. La amplitud del encuadre y penetración mediática parece ser el factor que más incide en la construcción de una democracia participativa.

Sin embargo, Wirth et al., (2010) llevaron a cabo un estudio en el que correlacionaron la prominencia de los argumentos mediáticos, públicos y políticos. Establecieron asociaciones positivas entre los argumentos públicos y políticos con los argumentos mediáticos en tres niveles de amplitud; baja, mediana y alta. Al comparar los discursos mediáticos de alta y baja influencia, los

"Los estudios del efecto de

la intensidad difusora han

establecido relaciones

positivas entre la ideología

politica, el nivel de

estudios, el tiempo de

residencia y el sexo con

respecto al consumo de

noticias.'

autores encontraron que las asociaciones fueron significativas en un solo nivel de amplitud intermedio, ni muy alto ni muy bajo. Es decir, la influencia de los medios en la opinión pública y las campañas políticas sólo se torna significativa en un nivel de encuadre intermedio. Aquellos medios de comunicación con una amplia difusión o baja amplitud no influyeron significativamente en los discursos públicos y políticos. Tales hallazgos son relevantes para el presente estudio ya que, los medios impresos de circulación nacional o circulación local podrían no influir en la opinión pública de una demarcación.
A diferencia de los estudios del efecto agenda, los estudios del efecto encuadre observan que el estilo de comunicación incide más que la amplitud del medio. A partir del supuesto según el cual el establecimiento de la agenda estaría indicado por efectos de encuadre más que por la correlación entre los contenidos mediáticos y los temas de opinión pública (Von Krogh, 2012).

García (2011) llevó a cabo un trabajo de sistematización de los encuadres noticiosos y encontró una relación positiva con los temas de opinión pública. La intensificación de editoriales y notas alusivas a un conflicto bélico en tres periódicos de circulación nacional correspondió con el aumento de las actitudes hacia guerra. Es decir, los medios impresos encerraban sus noticias con frases críticas a la actuación del gobierno español frente al conflicto de los Estados Unidos de América (EUA) versus Irak y ello pareció incidir en las actitudes hacia la política bélica de EUA, así como una relación positiva entre el número de encuadres y las actitudes hacia Saddam Hussein, ex gobernante de Irak. Por su parte, en el periódico $\mathrm{ABC}$ la relación fue negativa ya que la ausencia de editoriales $\mathrm{y}$ notas incrementó la actitud hacia el líder de Irak.

El efecto encuadre parece tener una relación estrecha con el manejo de la información circundante del tema en cuestión, la formación de actitudes y la toma de decisiones. En el trabajo de Bizer, Larsen y Petty (2010) el efecto de encuadre tuvo una relación indirecta con la intención. A través de la certeza de la fuente, los estilos de encuadre y difusión incidieron sobre las decisiones de los individuos. Al comparar la relación directa con la indirecta, el efecto de encuadre parece haber sido incrementado por la mediación de la credibilidad de la fuente.

Es posible suponer que el estilo de información y comunicación de la fuente parece haber influido sobre las decisiones de llevar a cabo un comportamiento vinculado con el objeto de encuadre. La inseguridad 
diseminada en el estilo del comunicador podría influir en las intenciones precautorias de las audiencias. En el caso de los medios impresos, los editoriales y columnas de opinión de una fuente confiable podrían incidir sobre las medidas de precaución por parte de algunos lectores (Mao et al., 2012).

Los estudios del efecto del encuadre mediático parecen ser un puente entre el efecto del establecimiento de la agenda y el efecto de la intensidad de su difusión mediática. A diferencia de estos, los estudios del efecto del encuadre se circunscriben a explicar el efecto de la política de los medios de comunicación sobre la cognición individual. Se trata de un proceso complejo en el que la cantidad de mensajes y expresiones de opinión pública estarían relacionadas por los estilos de comunicación y los estilos de expresión. Incluso, el poder persuasivo de los encuadres parece incrementarse con los estilos implicados en la difusión de un mensaje (García, 2010).

Sin embargo, la explicación en torno a la incidencia directa y significativa entre las estrategias de difusión y los comentarios de la opinión pública parece ser afectada por factores diversos. Los estudios del efecto de la intensidad difusora han establecido relaciones positivas entre la ideología política, el nivel de estudios, el tiempo de residencia y el sexo con respecto al consumo de noticias. También han diagnosticado las percepciones de la ciudadanía con respecto a los contenidos de los medios de comunicació n (Navarro, Climent y Fernández, 2012).

El efecto de intensidad mediática explica la relación entre los rasgos de difusión y las percepciones, creencias, actitudes, conocimientos, motivos, decisiones y acciones de los individuos. Mientras que las frases de los medios de comunicación respecto a un tema tienen un propósito persuasivo o disuasivo según la fuente y el tipo de receptor, la formación de actitudes obedecería a dos procesos: uno deliberado y otro espontáneo concurrentes el pensamiento social y la cognición personal.
Los medios de comunicación pueden difundir mensajes con un contenido ideológico de izquierda o derecha política, esta información competiría con otros mensajes que el receptor bien podría internalizar o procesar y adoptar cognitivamente. Los medios impresos orillan a que sus lectores decodifiquen frases y mensajes ajustados a sus creencias, o bien, procesar información contraria a sus expectativas. Tal proceso implicaría una estrategia deliberada, planificada y sistemática alejada de los lectores pasivos, considerando que la población lee un libro y medio al año, el procesamiento automático o espontáneo de la información basada en imágenes parece explicar el efecto de intensidad mediática (Wasike, 2013).

Antes bien, la percepción ciudadana en torno a los contenidos de la prensa parece estar más próxima a la desconfianza. Flores y Mendieta (2012) encontraron mayores porcentajes en la percepción negativa de la prensa. En su mayoría, los lectores consideran que los contenidos incitan a la violencia. En este estudio, la activación de emociones tales como, enojo, tristeza, desagrado e inseguridad podrían estar relacionados con acontecimientos difundidos por otros medios de comunicación que al ser asociados con las notas de prensa complementarían un ciclo de persuasión en el que los medios de comunicación masiva estarían difundiendo escenarios disuasivos de la paz pública.

El trabajo de Campillo (2012) muestra que la difusión de la seguridad pública es proporcionalmente neutral y supera el sesgo a favor o en contra en una muestra revisada de 1995 a 2007, aunque el encuadre de la prensa es considerado como fortuito por la ciudadanía respecto al tema de la inseguridad. Tal hallazgo, corrobora la hipótesis en torno a la cual la incidencia de los medios impresos parece ser explicada por un procesamiento automático o espontáneo de la información más que por un procesamiento deliberado, planificado y sistemático. Es decir, los lectores de la prensa, local o nacional, serían persuadidos por 
contenidos que incluyen imágenes y frases que activarían experiencias previas de inseguridad, decisiones y acciones improvisadas de prevención.

A partir de que la ciudadanía percibe a los medios de comunicación como emisores de contenidos nocivos para la democracia, la equidad y la paz pública, los estudios del efecto intensidad se han enfocado en la relación existente entre los mensajes y los receptores. Fenoll (2011) llevó a cabo un estudio en el que estableció una relación significativa entre las ideologías conservadoras y la pasividad de los usuarios. En dicho trabajo, la complejidad del mensaje

A partir de los estudios
citados, la mediatización
puede ser definida como la
recepción de contextos,
encuadres, intensidades y
direcciones en torno a las
noticias de riesgo o
seguridad, incredulidad o
confianza relativas..."

parece influir en el receptor activo o racional ya que incentiva su crítica. En contraste, los mensajes ideológicos relativamente simples, tuvieron un mayor efecto en aquellas audiencias conservadoras que tendían a la conformidad más que a la innovación.

A partir de tales hallazgos es posible suponer que, en el tema de la inseguridad, el efecto intensidad explicaría la incidencia sistemática de los mensajes sobre la opinión pública, más propiamente sus cogniciones; percepciones, creencias, actitudes, intenciones y acciones en interrelación con sus características socioeconómicas, demográficas y educativas (Orozco y Franco, 2012).
Nisbet, Stoycheff y Pearce (2012) establecieron el efecto directo del uso de internet (género, escolaridad y residencia) sobre la demanda ciudadana de democracia. A medida que los hombres, tienen un mayor nivel académico y han permanecido en la localidad, incrementan sus demandas de información relacionada con la democracia.

Por su parte Humanes y Moreno (2012) encontraron que el sexo repercutía en el consumo de noticias relativas a la inmigración mientras que la ideología repercutía en las noticias alusivas al terrorismo. Tales hallazgos, para los propósitos del presente estudio, podrían ser extendidos a la noción de seguridad pública. A medida que los hombres, profesionistas y con mayor arraigo son testigos de los hechos de violencia, buscarían información alusiva a la delincuencia a partir de las notas informativas de la prensa nacional, regional o local.

La activación automática y deliberada de las audiencias, sus decisiones y acciones precautorias podría deberse a la incidencia de acontecimientos sesgados por la prensa. Tal hipótesis podría enriquecerse si se contrastan los contenidos de la prensa local con los periódicos de circulación nacional (Ulloa, 2012).

Los estudios del efecto de la intensidad mediática parecen demostrar que los contenidos periodísticos al estar focalizados en las problemáticas locales activarían emociones que corresponderían con decisiones y acciones imprevistas en sus lectores. El sesgo de los rotativos en su encuadre de los hechos y las diferencias entre los diarios locales, parecen evidenciar un entramado de noticias sin restricción que a pesar de su sistemática difusión tendrían efectos diferenciados en los receptores (Izquierdo, 2012).

Rodríguez (2011) con una muestra de 139 noticias demostraron, a través de un análisis de contenido, las similitudes entre los contextos nacionales y locales en torno al encuadre de un área protegida. Tales 
convergencias activaron el efecto de la intensidad de los mensajes en la opinión pública tanto nacional como local.

A partir de los estudios citados, la mediatización puede ser definida como la recepción de contextos, encuadres, intensidades y direcciones en torno a las noticias de riesgo o seguridad, incredulidad o confianza relativas la violencia, la delincuencia y la injusticia, pero también alusivas a la confianza, el autocuidado y la pacificación (Latorre, 2011).

-Formulación: ¿Cuáles son las relaciones entre los encuadres y lógicas de verosimilitud o verificabilidad en una muestra de notas de prensa relativas a la seguridad pública de diarios de circulación nacional con respecto a las preferencias electorales, intenciones de voto y sufragios en 2012 de sus lectores observadas en los resultados de los comicios locales y federales?

-Hipótesis de simplicidad: En virtud de que, en las emociones derivadas de los encuadres de las notas de prensa relativas a la seguridad pública, antecede una lógica de verosimilitud, esta pudo incidir a partir de las emociones sobre las preferencias electorales, intenciones de voto y sufragios en las elecciones de 2012.

-Hipótesis de complejidad: No obstante que los encuadres y lógicas de las notas de prensa, relativas a la seguridad pública, son en su mayoría de verosimilitud, las preferencias electorales, las intenciones de voto y los sufragios cometidos en 2012 son determinadas por la compra de votantes. Por consiguiente, la lógica de verificabilidad incide sobre los lectores más que la lógica de verosimilitud, aunque en menor medida dada la minoría de sus lectores profesionistas y con consecuencias espurias en su formación ciudadana y elección de representantes. O bien, ambas lógicas de verosimilitud y verificabilidad al no incidir en los lectores votantes evidencian más un encuadre colateral o neutral que explica el desinterés tanto en los temas de la agenda como en los candidatos.

\section{MATERIALES Y MÉTODOS}

Se llevó a cabo un estudio documental, exploratorio, cualitativo, transversal y retrospectivo.

Se realizó un muestreo no probabilístico de 1000 extractos informativos en torno a la seguridad pública, ciudadana y privada de julio de 2011 a julio de 2013. Los criterios de elección de los extractos, siguiendo la lógica de verosimilitud y la lógica de verificabilidad, fueron la circulación nacional, referencia espacial, actualidad informativa, extensión del contenido, claridad expositiva, datos estadísticos y sondeos de opinión pública.

En virtud de que los estudios del encuadre de verosimilitud se rigen por un método ortodoxo en el que se construye un índice para establecer la correlación entre la frecuencia de los temas en las notas de prensa respecto al procesamiento de información de las audiencias, fue preciso reproducir el método a partir de la técnica Delphi para la selección, comparación e integración de la información, así como la elaboración de una matriz de análisis de contenido desde la que fue posible inferir los hallazgos.

El proceso de construcción de la matriz de análisis de contenido fue el siguiente:

1. La información fue seleccionada considerando el primer párrafo correspondiente con el encabezado de la nota de prensa.

2. Los párrafos seleccionados fueron incluidos junto con los datos fecha, encabezado y fuente.

3. Una vez estructurados los párrafos o extractos estos fueron analizados desde las categorías de establecimiento de la agenda, encuadre e influencia.

4. Las categorías utilizadas fueron; asaltos, agresiones, robos, secuestros, extorsiones, impunidades, corrupciones, prevenciones e imparticiones de justicia. 
5. 3 jueces; uno académico, otro político y otro periodista evaluaron la información de la matriz, asignándoles un valor de -1 para la información sesgada en un sentido negativo, pero inconsistente entre encabezado y contenido como sería el caso de un encabezado "40 mil muertes en el sexenio de Calderón" y un contenido en el que la cantidad de muertos no se incluyera.

6. Los jueces también asignaron un valor de 0 a aquella información en la que el encabezado y el contenido no incluyeron información relativa a la seguridad pública y sólo aludían a ella como un

"Es así como la

importancia de analizar un

periódico, aparentemente

neutral en la contienda

electoral y en la medida

en que los comicios se

aproximan, radica en la credibilidad de la fuente."

contexto sin profundizar en la difusión de un dato o hecho. Es el caso del encabezado: "En el sexenio de Calderón más defunciones" que correspondió con un contenido relativo a las muertes por una enfermedad crónica degenerativa.

7. En el caso de la información que incluía un encabezado que correspondía con un contenido relativo a la seguridad se le asignó un valor de 1. Es el caso del encabezado: "El sexenio de Calderón en más sangriento" que correspondió un reporte especial del número de víctimas durante el periodo citado.
8. Las evaluaciones de los tres jueces fueron sumadas para establecer un índice de Encuadre de la Seguridad Pública, la cual se interpretó a partir de tres umbrales que van de -300 a -1 el cual se asumió como un encuadre negativo; de 1 a 100 puntos considerado como bajo encuadre, de 101 a 200 como mediano encuadre y de 201 a 300 como alto encuadre.

\section{Resultados}

Durante el periodo que va de julio 2011 al mismo mes de 2013, el periódico "El Universal" reportó un encuadre intermitente de los hechos de inseguridad pública. En dicho periodo, los hechos de inseguridad tuvieron un encuadre sustancioso en el mes de septiembre 2012 cuando alcanzó un valor de 45 puntos.

Cabe señalar que, durante las precampañas que van de julio a octubre de 2011, el periódico citado llevó a cabo un encuadre decreciente. Se observa una disminución de hasta el $90 \%$ de las noticias.

En cuanto al periodo de veda electoral que comprende los meses de febrero, marzo y abril de 2012, el periódico aludido tuvo una disminución estrepitosa de 0 puntos en febrero, 9 puntos en marzo y un ligero despunte en abril con 7 puntos.

Mención especial merece el mes de julio 2012 en el que se llevaron a cabo las elecciones presidenciales, el cual registró un encuadre de 10 notas relativas a la seguridad pública.

"El Universal" manejó un discurso político de derecha que pudo ubicarse en un encuadre alto. La frecuencia de sus notas avala dicha postura ya que, en los meses más importantes el periódico realizó mínimos encuadres que le permitieron mantenerse en un margen de neutralidad respecto a la posible influencia con el electorado.

En el mes de septiembre de 2012 "El Universal" sistemáticamente llevó a cabo un encuadre mediático alto, revelando una tendencia desfavorable a la política de 
seguridad nacional. En contraste, la agenda política refería a la rectoría del Estado en materia de seguridad. Las notas reportadas indican una lógica de verificabilidad con excepción del mes de septiembre de 2012 el cual incluyó 35 noticias.

\section{Discusión}

En el periodo que va de julio de 2011 a julio de 2013, el periódico "El Universal" mantuvo un sesgo discreto en materia de seguridad, reduciéndose significativamente en el mes de julio de 2012 en el que se celebraron los comicios federales en México. Se trata del establecimiento de una agenda mediática, la cual incluye un encuadre y una lógica de verosimilitud que, sin embargo, parece no haber influido en las elecciones presidenciales ya que, el partido en el poder quedo en tercer lugar siendo otro partido el ganador de estos comicios.

Tal hallazgo corresponde con los resultados del estudio de Wirth et al., (2010) en donde encontraron que cuando la fuente informativa tiene una mediana cobertura de los hechos y por consiguiente adopta un estilo moderado de informar, discutir y críticas los hechos, entonces genera una alta expectación que se verá reflejada en una acción colectiva o movilización social.

La difusión de la seguridad pública en el periódico "El Universal" al ser cobertura nacional y al adoptar un encuadre de verosimilitud con sus lectores propiciaría una baja influencia en la preferencia electoral, intención de voto y sufragio efectivo para los comicios celebrados en 2012 y muy probablemente para las elecciones de 2018 si el ciclo de encuadre se repite.

Sólo en el mes de septiembre de 2012, el diario de circulación nacional llevó a cabo un encuadre con una lógica de verificabilidad, pero al no haber sistematizado esta tendencia en los meses previos a las elecciones no es posible atribuirle alguna influencia en la preferencia electoral, la intención de voto y el sufragio efectivo, los cuales estarían reflejados en el apoyo a un candidato diferente al del partido en el poder.
En este sentido, García (2011) analizando el encuadre de verosimilitud de la prensa española frente al conflicto entre EUA e Irak pudo correlacionar el sesgo informativo de mediana intensidad respecto a las actitudes hacia Sadam Husein, pero cuando el encuadre de verificabilidad fue empleado por la prensa española, la correlación con las actitudes hacia el conflicto bélico fueron negativas. Es decir, una mayor difusión del conflicto bélico centrado en imágenes generó un apoyo hacia el régimen de Husein, pero una difusión intensiva de los hechos verificables propició una imagen negativa hacia el gobierno de Irak.

En el presente trabajo, el rotativo "El Universal" difundió moderadamente información en contra y a favor del gobierno de Felipe Calderón Hinojosa, pero sin poder incidir en las preferencias electorales, las intenciones de voto o el sufragio efectivo de los electores ya que, a diferencia del estudio en el que la prensa difundió moderada y sistemáticamente imágenes y hechos sorbe el conflicto bélico entre EUA e Irak, polarizando las actitudes de los lectores hacia el gobierno de Sadam Husein, en el presente estudio la prensa mexicana no combinó ambos encuadres.

Incluso, la prensa mexicana sólo utilizó moderada, pero no sistemáticamente el encuadre de verosimilitud durante la contienda electoral y los comicios de 2012. Además, ese encuadre de verosimilitud fue reduciéndose conforme se acercaban los comicios federales y presidenciales en México.

De este modo, las elecciones de 2018 podrían reflejar la ausencia de un encuadre sistemático de verosimilitud y verificabilidad. Esto sería así porque la prensa mexicana en general y el diario "El Universal" en particular no intensifica su sesgo informativo y más bien genera una especie de "Anti Agenda" centrada en la indiferencia hacia la contienda electoral, los candidatos y las elecciones. Se trata de un proceso inverso al establecimiento de una agenda que está lejos de difundir temas de debate que generen un consenso o una tendencia a favor o en contra de una opción partidista. 
Es así como la importancia de analizar un periódico, aparentemente neutral en la contienda electoral y en la medida en que los comicios se aproximan, radica en la credibilidad de la fuente que Bizer, Larsen y Petty (2010) han estudiado como una variable mediadora del efecto de agenda y encuadre, pero que en el presente estudio es una variable predecible a partir de la prevalencia del encuadre de verosimilitud y la baja intensidad del sesgo informativo.

Es decir, el periódico "El Universal" parece orientar su sesgo informativo hacia lectores que procesan información a partir de imágenes o encabezados más que en el análisis del

\section{"La hipótesis de}

simplicidad radica en que

la difusión intensiva de las

imágenes propiciaría una

desesperanza emocional

generalizada en los

electores de tal manera

que afectaría sus

preferencias electorales..."

contenido de las notas o su comparación con otras fuentes informativas. Esto es así porque al parecer el rotativo tiene una baja credibilidad como fuente informativa, o bien, si su credibilidad es moderada o incluso alta, no la contrastan al suprimir de su difusión el encuadre de verificabilidad.

De este modo, si el diario de circulación nacional difundiera la información con un encuadre de verificabilidad, entonces no sólo incrementaría la capacidad crítica de sus lectores sino, además propiciaría un cuestionamiento a su propia difusión ya que, una nota de prensa podría ser contrastada con otra nota de prensa en la misma edición de una semana o un día como el de los comicios presidenciales de 2012 y 2018.

Es en este sentido que, si en el 2012 prevaleció un encuadre de verosimilitud incompleto, se esperaría que para los comicios de 2018 la difusión se mantenga intacta, reduciendo la contienda electoral a su mínima expresión porque los electores no tendrían material verificable con el cual debatir, tomar decisiones y sufragar en ese mismo sentido.

Por consiguiente, los comicios federales de 2018 serán un escenario similar al ocurrido en 2012, con acto res o candidato $\mathrm{s}$ diferentes, pero con una estructura mediática similar a la de 2012. Es decir, un escenario en el que los medios no parecen informar siquiera con imágenes los aportes de candidatos, las diferencias entre los partidos y las tendencias o intenciones de voto que orienten un sufragio razonado, deliberado y sistemático.

Ambas lógicas, verosimilitud y verificabilidad, parecen no haber influido, ya sea porque el candidato del partido en el poder no fue electo, o bien, porque alguna de ellas se registró posterior a los comicios. Esto es así porque los medios impresos, particularmente el diario "El Universal" ajustan su encuadre informativo a una lógica de verosimilitud para influir en lectores cuyas preferencias electorales, intenciones de voto y sufragios son comprados por cada uno de los partidos contendientes, antes y durante los comicios.

Es decir que, los partidos políticos no representan los intereses del electorado hasta que se aproximan los comicios e incentivan al electorado con objetos o dinero para inducir su apoyo en las encuestas y después en las elecciones. Por consiguiente, los medios impresos no son un instrumento de establecimiento de agenda pública, encuadre sociopolítico y lógica de verosimilitud o verificabilidad para influir en los lectores en edad de votar.

Los partidos políticos, los candidatos y la contienda electoral en México al ser diversos en su ideología y a la vez pragmáticos en su 
proselitismo, no requieren de los medios de comunicación en general ni de los medios impresos en particular para definir una campaña electoral (Zúñiga, 2012). En contraste, las elecciones realizadas en países como Estados Unidos de América, Reino Unido, Alemania, Francia o España parecen ser influidas por los medios de comunicación tradicionales, principalmente las redes digitales como Facebook, Twitter o Instagram al momento de definir una preferencia electoral, intención de voto o sufragio efectivo (Zaffaroni, 2011).

La penetración de las redes digitales en México ha sido creciente y para los comicios a celebrarse en 2018 se espera que estas definan una parte de la contienda y preferencia electoral, así como la intención de voto y el sufragio, pero si el nivel de pobreza extrema se incrementa en México, entonces los partidos políticos y los candidatos reproducirán la estrategia de compra del voto con la finalidad de definir la balanza a su favor.

Por consiguiente, el aporte del presente trabajo al estado de la cuestión radica en el diagnóstico del establecimiento de agenda, encuadre y lógica de difusión de información concerniente a la seguridad pública en el periodo que va de julio de 2011 a 2012, pero cuyos hallazgos podrían observarse en el periodo julio 2017 a julio de 2018 si la pobreza extrema se incrementa en México, o bien, si los partidos políticos recaudan los fondos necesarios para comprar el voto en los electores más necesitados.

Incluso, el presente estudio es relevante en cuanto a que propone una metodología para observar la influencia de los medios impresos en un periodo anterior y posterior a los comicios. Si es que efectivamente la democracia mexicana se consolida, entonces la incidencia mediática se podría observar en los comicios de 2018, pero si más bien la transición hacia la democracia es todavía vigente, entonces la nula influencia de los medios en las elecciones será una evidencia poco determinante de los sufragios en particular y los comicios en general.

\section{Conclusión}

El objetivo del presente trabajo ha sido explorar el encuadre de verosimilitud del periódico "El Universal" con respecto a la seguridad pública y en relación con la imagen del gobierno de Felipe Calderón Hinojosa. la contienda política, los comicios presidenciales, la preferencia electoral, la intención de voto y el sufragio efectivo.

En tal sentido, la pregunta de investigación refiere a la prevalencia del encuadre de verosimilitud centrada en la difusión de imágenes y la activación de emociones en el electorado durante el periodo que va de julio de 2011 a julio de 2012 con respecto al encuadre de verificabilidad centrado en la difusión de cifras y datos verificables en otras fuentes informativas que activarían una reflexión en torno a la seguridad pública y sus implicaciones en los comicios federales.

La hipótesis de simplicidad radica en que la difusión intensiva de las imágenes propiciaría una desesperanza emocional generalizada en los electores de tal manera que afectaría sus preferencias electorales, intenciones de voto $\mathrm{y}$ sufragio efectivo, beneficiando al candidato del partido en el poder ya que con su partido apostaron por una campaña del "miedo" en la que la activación de emociones suponía el inicio del proceso persuasivo de emisión del voto a cambio de seguridad mediante una campaña de "mano dura" contra la delincuencia .

La hipótesis de complejidad supuso más bien que otros factores externos al establecimiento de la agenda y el encuadre determinarían las preferencias electorales, intenciones de voto y sufragio efectivo del electorado.

Sin embargo, la difusión moderada y aparentemente neutral del periódico "El Universal" cuyas notas de prensa relativas a la seguridad pública fueron reduciéndose conforme se exacerbada la contienda electoral y se aproximaban los comicios, orientaron la discusión a la credibilidad de la fuente: su capacidad de influencia y contribución al debate electoral y el consenso social. 
De esta manera, es posible advertir que el escenario de investigación de julio de 2011 a julio de 2012 parece anticipar el escenario de julio de 2017 a julio de 2018 si la prensa mexicana en general y el periódico "El Universal" en particular: 1) privilegian un encuadre de verosimilitud sobre el encuadre de verificabilidad; 2) reproducen una difusión aparentemente neutral de baja intensidad con respecto a la seguridad y del gobierno del presidente Enrique Peña Nieto; 3) reducen su encuadre conforme la contienda electoral se intensifica y las elecciones se acercan.

\section{REFERENCIAS}

Acosta, J. (2010). Violencia política y derechos humanos. Universitaria, 11, 1-13

Añez, M., Rujano, R. y Párraga, J. (2011). Seguridad ciudadana y acceso a la justicia. Cuestiones Jurídicas, 5, $11-25$

Bizer, G., Larsen, J. y Petty, R. (2010). Exploring the valence framing effect: negative framing enhances attitude strength. Political Psychology, 32, 59-80

Borghello, C. y Temperi, M. (2012). Suplantando la identidad digital como delito informático. Revista de Informática y Derecho, 41, 78-93

Calderón, E. (2012). La impronta legal de la participación de las fuerzas armadas en seguridad pública: el caso de la lucha contra el narcotráfico en América del Sur. Revista Latinoamericana de Seguridad Ciudadana, 12, 97-109

Campillo, C. (2012). La gestión estratégica de la información municipal. Análisis de temas, su tratamiento e irrupción en el ayuntamiento del Elche (1995-2007). Revista de Estrategia, tendencia e Innovación de la Comunicación, $3,149-170$

Carcelén, R., Esteba, P. y Peyró, L. (2013). Tratamiento informativo de las drogas en medios de salud en España y su relación con la agenda científica. Revista Iberoamericana para la Investigación y el Desarrollo Educativo, 10, 1-35

Flores, L. y Mendieta, A. (2012). La percepción de la nota roja periodística en primera plana, un estudio de caso. Revista de Comunicación, 14, 1-13

García, C. (2012). Estructura de la inseguridad pública. Liberabit, 18, 37-44

García, C. (2013). La inseguridad migratoria en los medios impresos. Reflexiones, 92, 159-173

García, D. (2010). El derecho a la intimidad y el fenómeno de la extimidad. Dereito, 19, 269-284

García, J. (2011). Encuadres, conflictos y efectos de agenda. Revista Zer, 31, 167-181

González, C., Pombo, O., Méndez, H., Espejel, M. y Leyva, J. (2011). Representaciones mediáticas socioambientales. Revista Culturales, 13, 145-172

González, J., Hernández, A. y Garza, R. (2010). Modelo predictivo de las interacciones violentas en parejas jóvenes y prejuicio de género asociados. Revista Científica de Psicología, 10, 224-239
Groshek, J. (2011). Media, instability, a democracy: examining the granger causal relationships of the 122 countries from 1943-2003. Journal of Communication, 61, 1161-1182.

Gu, M. y Goldfarb, B. (2010). Affect and the framing effect witting individuals over time: risk taking in a dynamic investment simulation. Academic of Management Journal, 53, 411-431.

Guardiola, A., Espinar, E. y Hernández, I. (2010). Los inmigrantes como amenaza en la televisión española. Convergencia, 53, 59-58.

Humanes, M. y Moreno, M. (2012). El efecto agenda sobre los temas de campaña en las elecciones generales de 2008. Revista de Estrategia, Tendencia e Innovación de la Comunicación, 3, 191-207.

Izquierdo, L. (2012). La uniformidad temática en las secciones de internacional de los diarios madrileños frente a las secciones locales. Communication Papers, media Literacy \& Gender Studies, 1, 97-104.

Latorre, E. (2011). Visibilización de la memoria de las víctimas de la violencia en el departamento de Magdalena: Resiliencia para construir verdad jurídica. Prolegomenos, Derechos y Valores, 27, 199-212.

Mao, Y., Richter, M., Burns, K. y Chaw, J. (2012). Homelessness coverage, social reality, and media ownerships: comparing a national newspaper with to regional newspapers in Canada. Mass Communication \& Journalism, 2, 1-7.

Navarro, Y., Climent, J. y Fernández, J. (2012). Modelos de gestión de conflictos en serie de ficción televisiva. Escritos de Psicología, 5, 52-60.

Nisbet, E., Stoycheeff, E. y Pearce, K. (2012). Internet use and democratic demands: a multinational, multilevel model of Internet use and citizen attitudes about democracy. Journal of Communication, 62, 249-265

Orozco, G. y Franco, D. (2012). Las audiencias convergentes y su investigación: análisis de recepción transmedial de la serie El Equipo. Derecho a Comunicar, 5, 46-63

Rodríguez, F. (2011). Discurso xenófobo y fijación de agenda. Un estudio de caso en la prensa de Canarias (España). Revista Latina de Comunicación Social, 65, 222-230.

Salas, L. (2011). La seguridad pública y su apoyo en políticas públicas. Encrucijada Revista de Estudios en Administración Pública, 8, 1-12

Ulloa, I. (2012). El desafío de garantizar la seguridad pública: el modelo de seguridad pública. Seguridad y Ciudadanía, 7, 13-24

Von Krogh, T. (2012). Changing political attitudes towards media accountability in Sweden. Central European Journal of Communication, 2, 204-224

Wasike, B. (2013). Framing news in 140 characters: how social media editors frame the news and interact with audiences via twitter. Global Media Journal, 6, 5-23

Wirth, W., Matthes, J., Schemer, C., Wettstein, M., Friemel, T., Hânggli, R. y Siegert, G. (2010). Agenda building and setting in referendum campaign: investigating the flow of arguments among campaigners, the media, and the public. Journalism \& Mass Media Communication, 87, 328-345

Zaffaroni, R. (2011). Estado y seguridad pública: algunas consideraciones básicas. Cuadernos de Seguridad, 14, 17-32

Zúñiga, L. (2012). Desafíos institucionales de la colaboración policial-militar el triángulo norte. Revista Latinoamericana de Seguridad Ciudadana, 12, 83.96 
